Article

\title{
Effects of Incorporating AR into a Board Game on Learning Outcomes and Emotions in Health Education
}

\author{
Hao-Chiang Koong Lin ${ }^{1}$, Yu-Hsuan Lin ${ }^{1}{ }^{1}$, Tao-Hua Wang ${ }^{2}$, Lun-Ke $\mathrm{Su}^{3}$ and \\ Yueh-Min Huang ${ }^{2, *}$ \\ 1 Department of Information and Learning Technology; National University of Tainan, Tainan 700, Taiwan; \\ koong@gm2.nutn.edu.tw (H.-C.K.L.); m10455004@gm2.nutn.edu.tw (Y.-H.L.) \\ 2 Department of Engineering Science; National Cheng Kung University, University Road, Tainan 701, Taiwan; \\ t10455112@gm2.nutn.edu.tw \\ 3 Association of Siraya Culture, Gongyuan Rd, Tainan 704, Taiwan; su840306ko@gmail.com \\ * Correspondence: huang@mail.ncku.edu.tw; Tel.: +886-939-931-111
}

Received: 20 September 2020; Accepted: 20 October 2020; Published: 22 October 2020

\begin{abstract}
In traditional school education, the content of health education courses cannot be easily linked to daily life experiences. This results in the low application of acquired knowledge and hinders students from gaining hands-on experience and a sense of accomplishment through courses, thereby lowering the learners' engagement and willingness to learn. This study designed a board game integrated with augmented reality (AR) for health education; incorporated the card-game, slides, and learning-sheets (CSLS) gamification teaching model into the learning process; and discussed the effectiveness of board games with augmented reality in improving learning outcomes and emotions. The research participants were 52 senior high school students, who were assigned to the experimental (AR health education board game) or control (health education board game) group in the teaching experiment. The research findings reveal the following. The two groups were significantly different in terms of (1) learning outcomes, (2) negative emotions, (3) flow state in the game.
\end{abstract}

Keywords: game-based learning; augmented reality; board game; health education

\section{Introduction}

In traditional school education, students are commonly restricted by the education system, and the content of health education courses cannot be easily linked to learners' everyday experiences. Therefore, the application of acquired knowledge is relatively low, and it is difficult for learners to acquire hands-on experience and a sense of accomplishment in class. This causes insufficient engagement and low willingness to learn. Moreover, current standardized learning materials rarely elicit proactivity in learners. In recent years, game-based learning has rapidly developed. In comparison with traditional learning, which generally involves learners passively receiving knowledge from teachers, game-based learning offers more engaging learning experiences and improves learners' learning outcomes, thereby enabling learners to learn actively. Brown et al. [1] proposed the situated learning theory, which states that when learners learn in a real-life or simulated setting, they can acquire knowledge from their personal experiences and use such knowledge in flexible application scenarios. Situation is a combined product of the surrounding social environment, including people and social culture. Dunleavy et al. [2] suggested that augmented reality (AR) learning is consistent with situated learning and constructivism learning theory because AR situates learners in a real-world and social setting while also guiding and encouraging users in a constructed participatory and metacognitive learning process. Students are able to develop their knowledge in AR situations. AR learning leads students to engage with the targeted 
learning domain through situated learning; therefore, AR integrated with games provides a solution to the missing connection between health education courses and daily-life scenarios.

To enhance the diversity and integration of the playing process in learning, enrich learners' experience during game-based learning, and integrate their cognitive academic interpretation, the card-game, slides, and learning-sheets (CSLS) gamification teaching model has been introduced and incorporated into teaching situationally. Shen et al. [3] indicated that the CSLS teaching model increases interaction among peers, leads learners to develop their cognitive thinking abilities, and induces self-learning motivations. The CSLS teaching model improves learners' motivation to engage in self-learning and discussions and can be implemented in accordance with different teaching schedules. Therefore, this teaching model was incorporated into the present study to improve the smoothness of game-based learning.

We developed an augmented reality (AR)-based board game to be incorporated into health education to familiarize senior high school students with health education. Furthermore, we used CSLS as an auxiliary tool to assist learners in swiftly entering the state of learning, which further allowed students to absorb the relevant knowledge of health education while playing the game. The advanced post-test learning effectiveness scale, Achievement Emotions Questionnaire (AEQ), and flow experience were also used to probe the impact of AR in a board game on learning effectiveness, as well as its impact on the effectiveness and differences for tenth graders using this teaching tool for health education.

Based on the background and motives of this study as well as the abovementioned discussion, the objectives of this study were as follows:

(1) To discuss the effect of incorporating AR into the health education board game on learning outcomes.

(2) To discuss the effect of incorporating AR into the health education board game on learning emotions.

(3) To discuss the effect of incorporating AR into the health education board game on the flow state in the game.

\section{Related Work}

Health education in school touches upon various themes, including the usage and abuse of alcohol and other drugs, healthy diet/nutrition, mental and emotional health, personal health and health care, sports training, safety and injury prevention, sexual health, and smoking and violence prevention. The education, teaching, and subjects of traditional schools lean towards being disciplinary, and the content of health education is likely to be detached from real-life situations, which cannot be applied in actual scenarios, hence leading to the learners having no sense of participation and thereby reducing their willingness to learn [4]. Furthermore, with standardized learning materials, the initiative of the learners is rarely stimulated.

In view of the above literature, in this study, we placed emphasis on the health education of physiology, including the understanding of diseases and the alertness of symptoms, and incorporated CSLS to enhance the diversity and integration of the playing process in learning, and integrated the learners' cognitive academic interpretation.

AR refers to the addition of virtual objects in the real world. Numerous studies have indicated that AR can effectively elevate of learning [5-8]. A significant increase in academic performance with the use of AR has been found [9], hence the application of AR significantly improves learning effectiveness. Billinghurst et al. [10] pointed out that AR has compelling effects on education. The utilization of the AR application procedure in scientific laboratories can assist in completing experiments within the duration of the courses, they also mentioned that AR provides graphic materials visually, which effectively helps with conducting experiments [11]. The AR and creative design teaching solution proposed [12] significantly increased the learning motivation and creativity of the students. 
Game-based learning intends to integrate learning into games, where one can acquire knowledge through games, and learn relevant knowledge in a playful manner. Kafai [13] discovered that learning conducted through game-like approaches induces a higher level of willingness for children to learn than other auxiliary media, which substantially allows learners to perform actions and therefore helps with the memory of learning. In contrast to traditional education, game-based learning effectively increases the learning motivation of the students. Game-based learning offers a higher degree of satisfaction than traditional learning, as it allows them to acquire new knowledge under a pleasant stimulation and with desire [14]. Game-based learning may be superior to the traditional teaching conducted in classrooms and thus can increase the learning motivation of the students, while offering an opportunity to explore and acquire new knowledge and skills [15]. Games increase the students' learning motivation and in turn elevate the acquisition of knowledge; therefore, learners can grow in a positive and focused learning scenario in a playful environment [16].

The incorporation of board games into teaching has gradually become a mainstream method of teaching. Board game can stimulate the players' curiosity, facilitate interaction between participants, and serve as an auxiliary tool for knowledge construction [17]. Kuo [18] used a board game to effectively elevate elementary school students' attitude towards learning English as well as trigger learning interests and lower learning anxiety.

Gamification teaching activities using card games, slides and learning sheets, and CSLS are innovative teaching models developed by Mini Educational Game development group (NTUST MEG). Li et al. [19] used card games, slides, and learning sheets to design game-based learning, where the three media performed their respective functions. The card game design focused on peer interaction and self-learning motivation. Slides provided scenario import to help learners with concentration. Learning sheets helped learners to review the concepts.

Hence, one can conclude that a playful approach, where one can absorb knowledge at the same time, will cultivate attainment and multiple objectives. CSLS can achieve relatively good involvement and acceptance, and it is mentioned that it can elevate the learners' participation motivation in activities, as well as achieve adaptive scaffolding introduction, which further facilitates learning effectiveness [3].

Many previous studies have pointed out that combining AR with board games can improve learning effectiveness. Wang [20] points out that the combination of board games and AR teaching in drug education has significantly improved students' basic knowledge, life skills, subjective norms, perceptual behavior control, and behavioral intentions. Students also reported that the board game courses helped to raise awareness about substance abuse and enhanced learning effectiveness. Wang [21] developed a set of AR board games, named Ecological Restoration, which integrated the natural context of various ecosystems and presented biological knowledge clues using physical cards and AR technology as a cognitive scaffold to assist learners in learning. The research results show that learners displayed significant improvement in learning effectiveness after using this game. The above research indicates that the combination of AR and table games could improve students' learning effectiveness. We developed an augmented reality (AR)-based board game to be incorporated into health education to familiarize senior high school students with health education. Furthermore, we used CSLS as an auxiliary tool to assist learners in swiftly entering the state of learning, which further allowed students to absorb the relevant knowledge of health education while playing the game. To probe the impact of the incorporation of AR into a board game on learning effectiveness, as well as its impact on the effectiveness and differences for tenth graders, we used this teaching tool for health education. 


\section{Method}

\subsection{AR-Based Board Game for Health Education}

The health education board game designed in this study was based on the situated learning theory proposed by Brown [1]. The game combines augmented reality (AR) with health education to guide students and elicit their interest to learn. According to the scaffolding theory proposed by Wood et al. [22], we placed question cards in the health examination reports provided in the AR health education game, and textual descriptions or the correct answers were displayed on the back of each question card. Adding images and text to game cards concurs with the dual-coding theory proposed by Paivio [23], who asserted that this approach is conducive to students' learning. In addition, we referenced the concept of over-learning proposed by Ebbinghaus [24], players will be repeatedly practicing with question cards in the AR health education game upon revisiting specific locations. Through this, the game facilitates the students' understanding of their learned knowledge. Finally, the game mechanisms were designed by referencing the concept of competition-based learning proposed by Burguillo [25] to increase learners' learning motivation (see Table 1).

Table 1. Teaching mechanisms and the corresponding theories.

\begin{tabular}{|c|c|c|}
\hline Game Design Elements & Applied Theory & \\
\hline $\begin{array}{l}\text { Game scenarios } \\
\text { and card cues }\end{array}$ & $\begin{array}{l}\text { Situated learning theory } \\
\text { Brown [1] }\end{array}$ & $\begin{array}{l}\text { By employing the virtual reality environment, } \\
\text { learners with different subject knowledge or learning } \\
\text { characteristics can be guided to generate interest } \\
\text { in learning. }\end{array}$ \\
\hline AR information guidance and feedback & $\begin{array}{l}\text { Scaffolding theory } \\
\text { Wood [22] }\end{array}$ & $\begin{array}{l}\text { Providing systematic guidance and key instructions } \\
\text { to improve students' learning ability when they are } \\
\text { learning a new concept or skill. }\end{array}$ \\
\hline Card images and text & $\begin{array}{l}\text { Dual-coding theory } \\
\text { Paivio [23] }\end{array}$ & $\begin{array}{l}\text { Applying text, animation, pictures, and other } \\
\text { multimedia teaching materials to promote } \\
\text { learning efficiency. }\end{array}$ \\
\hline Repeatedly practice with problem solving cards & $\begin{array}{l}\text { Over-learning } \\
\text { Ebbinghaus [24] }\end{array}$ & $\begin{array}{l}\text { After the students have mastered the concepts they } \\
\text { have learned, they can deepen their understanding } \\
\text { or enhance their memory by repeatedly practicing } \\
\text { with the help of the problem-solving cards. }\end{array}$ \\
\hline Winning games through competition & $\begin{array}{l}\text { Competition-based Learning } \\
\text { Burguillo [25] }\end{array}$ & $\begin{array}{l}\text { Developing learning motivation and upgrading } \\
\text { performance through competition. }\end{array}$ \\
\hline
\end{tabular}

In this research, we focused on the course of health education, and then designed and produced a board game that integrated AR. Components of AR-based board game for health education (as shown in Figure 1 below) include eight subjects, namely Department of Otolaryngology (ENT), Department of Family Medicine (FM), Department of Obstetrics and Gynecology (OBS), Department of Genitourinary (GU), Department of Hematological and Oncology (ONC), Department of Neurology (NS), Department of Gastroenterology and Hepatology (GH), and Department of Chest Medicine (CM). The O or X in the Figure $1-\mathrm{O}$ and $\mathrm{X}$ indicate that the board game does and does not comprise this accessory, respectively. Experimental group: the AR-based board game can scan the AR report with a mobile device. In the augmented reality health education board game, question cards function as the AR identification map. When the identification map is placed on the AR report and scanned with a mobile vehicle, relevant information about the question will appear. Further, the control group designed graphics on the back of the question cards of the health education board game to provide non-AR version students with the same information. 


\begin{tabular}{|c|c|c|c|}
\hline Game Component & Component Explanation & NOAR & $\mathrm{AR}$ \\
\hline 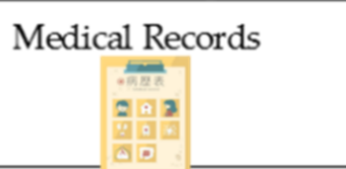 & $\begin{array}{l}\text { Collect eight different subjects as fast } \\
\text { as possible, and complete the medical } \\
\text { records to be the winner }\end{array}$ & $\mathrm{O}$ & $\mathrm{O}$ \\
\hline 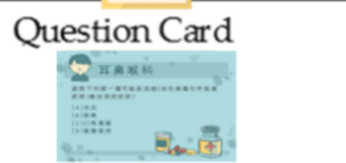 & $\begin{array}{l}\text { Eight subjects, and approximately } 56 \\
\text { questions including ENT, FM, OBS, } \\
\text { GU, ONC, NS, HG, and CM }\end{array}$ & $\begin{array}{l}\text { O } \\
\text { Answer on } \\
\text { the back }\end{array}$ & $\begin{array}{l}\mathrm{O} \\
\text { No answer } \\
\text { on the back }\end{array}$ \\
\hline 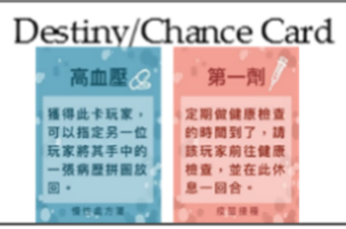 & $\begin{array}{l}\text { The Destiny Card will have to be used } \\
\text { immediately. The Chance Card can } \\
\text { either be used right away or kept as a } \\
\text { card on hand. }\end{array}$ & $\mathrm{O}$ & $\mathrm{O}$ \\
\hline Other Accessories & Characters, dice, and maps & $\mathrm{O}$ & $\mathrm{O}$ \\
\hline AR Report & $\begin{array}{l}\text { Scan the AR Report with a tablet. The } \\
\text { results and information related to the } \\
\text { AR Report will then display on the } \\
\text { tablet. }\end{array}$ & $x$ & $\mathrm{O}$ \\
\hline Tablet & $\begin{array}{l}\text { Scan the AR Report using a mobile } \\
\text { device. }\end{array}$ & $x$ & $\mathrm{O}$ \\
\hline
\end{tabular}

Figure 1. Components of augmented reality board game for health education.

\subsection{Experimental Process}

Apart from exploring how incorporating the AR-based board game with the assistance of CSLS improves the learning effectiveness of health education for senior high school students, in this study, we implemented a measurement of the students' learning emotion, and the definition of game flow.

As shown in Figure 2, the two groups of students were randomly allocated into the control group and the experimental group, and before the commencement of the guided teaching, a 15 min pre-test was implemented, followed by CSLS, where a $5 \mathrm{~min}$ presentation was utilized to trigger the students' motivation. The control group underwent 45 min game-based learning with a general board game paired with a learning sheet, whereas the experimental group underwent 45 min game-based learning with an AR-based board game paired with a learning sheet, where the teaching content was rendered on mobile devices through the effect from the integration of the virtual and reality worlds, in order to create a different sensory experience. A 25 min post-test (as shown in Figure 2 below) was implemented after the completion of the teaching activities. Figure 3 is the research conceptual framework. Figure 4 shows the experimental group playing scene. Figure 5 shows the control group playing scene. 


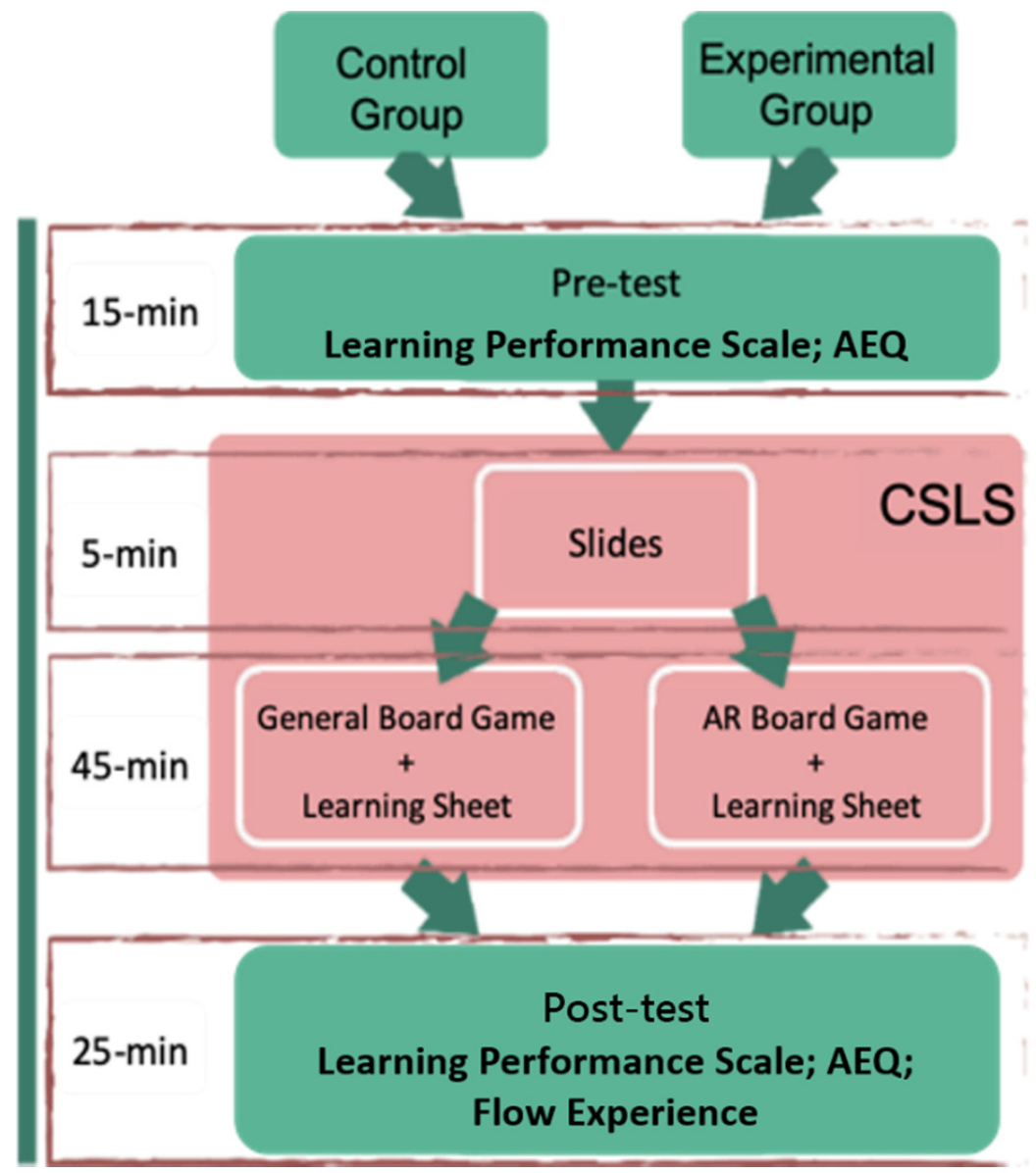

Figure 2. The research process flowchart.

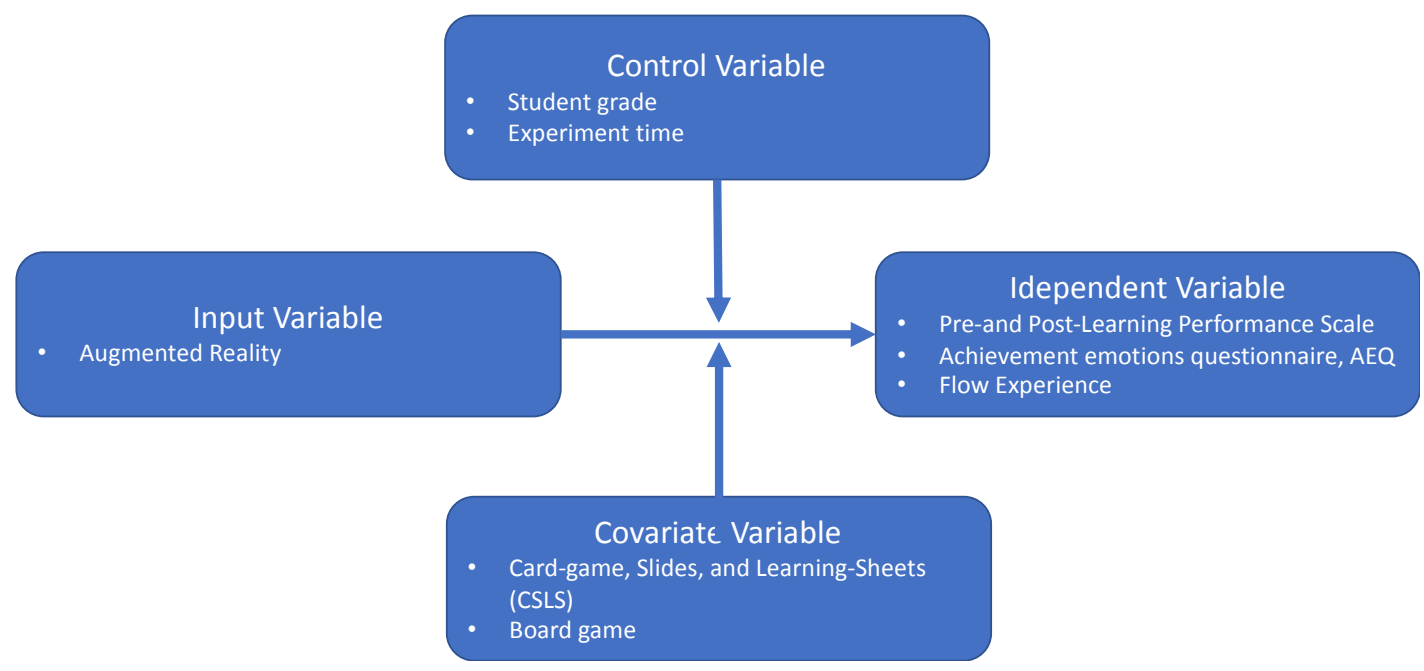

Figure 3. The research conceptual framework. 


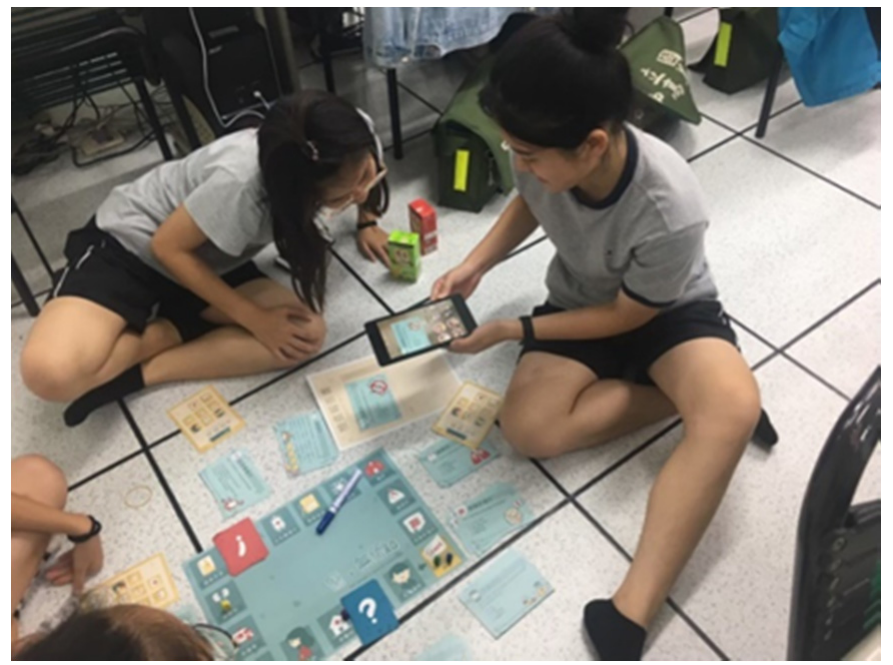

Figure 4. Experimental group playing scene.

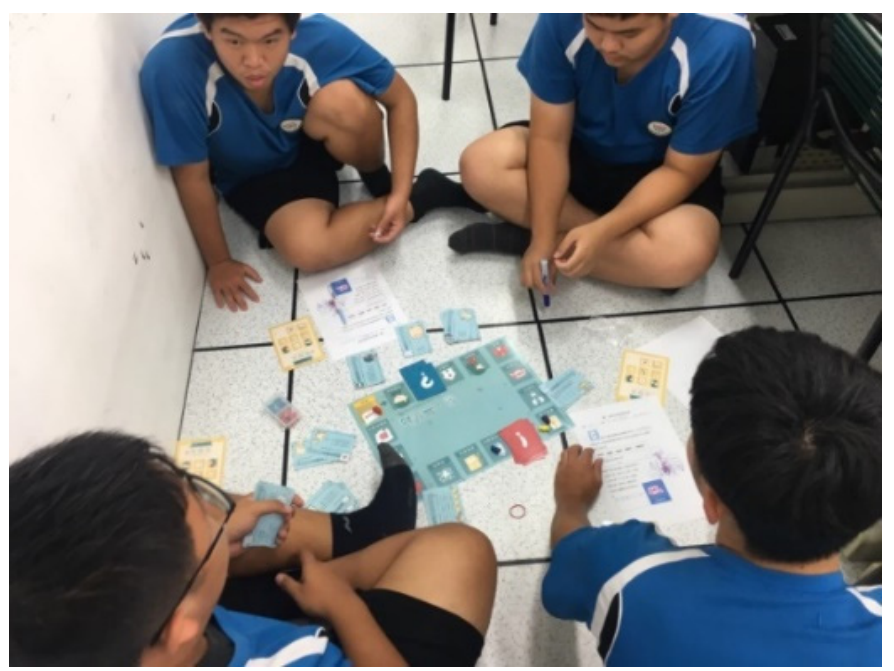

Figure 5. Control group playing scene.

\subsection{Participants}

The participants of the study were tenth graders from a high school located in southern Taiwan. The sample size was 52, and the students were divided into the control group and the experimental group, with 25 students in the control group, and 27 students in the experimental group, who played a general health education board game and an AR-based health education board game, respectively, and groups of three to four people were then formed within both the groups.

\subsection{Research Tool}

\subsubsection{Pre-and Post-Learning Performance Scale}

In all, 56 questions are asked from eight subjects, namely ENT, FM, OBS, GU, ONC, NS, GH, and CM. They were selected and organized to facilitate the compilation of the pre- and post-learning performance scale. Of the 52 questions, 25 were quantified items and were multiple-choice questions, and only the order of the questions and options were changed from the pre-test to the post-test. This scale was evaluated by three experts (see Table 2). 
Table 2. Participating evaluation specialists' background and experience.

\begin{tabular}{ccc}
\hline Specialist & Background & Experience \\
\hline A & Doctor & 6th year as a resident doctor \\
B & Nurse & 10 years in the clinic \\
C & Nurse & 13 years in clinical nursing activity \\
\hline
\end{tabular}

\subsubsection{Achievement Emotions Questionnaire, AEQ}

Pekrun, Goetz and Perry [26] conceived the Achievement Emotions Questionnaire (AEQ) based on exploratory studies identifying the emotions reported by students in academic situations. The AEQ includes nine different emotions (enjoyment, hope, pride, relief, anger, anxiety, hopelessness, shame, and boredom), in this study, the original questionnaire was revised to analyze the eight emotions according to the research needs. In order to understand the learners' manifestation of emotion during the experience of the AR-based board game, we used this scale, which is divided into three sections, namely before learning, during learning, and after learning, with a total of 75 questions.

\subsubsection{Flow Experience}

In order to explore the learners' flow status during the experience of the AR-based board game, we adopted the flow questionnaire designed by Kiili [27] and the Chinese version designed by Hou and Chou [28]. The flow experience was also divided into two dimensions, the means of the flow antecedents and the indicators of flow experience. This is a Likert-scale 5 point questionnaire.

\section{Results}

\subsection{Evaluation of Learning Effectiveness}

\subsubsection{Pre-and Post-Learning Performance Scale}

As shown in Table 3, The interaction terms for the independent variables and the covariances were $F(1,48)=0.026, p=0.873$, and a significance of $0.873>0.05$, which did not render a significant level, indicating that the linear relationship between the independent variables and the dependent variables from each group was consistent. Thus, an analysis of covariance could be implemented.

Table 3. Test results of homogeneity of regression coefficients in the pre-test group.

\begin{tabular}{cccccc}
\hline Source of Variation & $S S$ & $d f$ & $M S$ & $\boldsymbol{F}$-Test & $p$-Value \\
\hline Group & 234.235 & 1 & 234.235 & 0.602 & 0.43 \\
Pre-test & 4419.362 & 1 & 349.60 & 11.359 & 0.003 \\
Group Pre-test & 10.024 & 1 & 10.024 & 0.026 & 0.873 \\
Error (between groups) & 18675.319 & 48 & 389.069 & & \\
\hline
\end{tabular}

Note: sum of squares (SS), degree of freedom $(d f)$, mean square $(M S)$.

As shown in Table 4, the results of the covariate analysis were $F(1,49)=2.094, p=0.001$, and a significance of $0.001<0.05$, which implied that the differences between groups reached a significant level, thereby indicating that there were significant differences in the performance score between the two groups undergoing different learning methods.

Table 4. Analysis of covariance: learning effectiveness of two groups.

\begin{tabular}{|c|c|c|c|c|c|}
\hline Source of Variation & SS & $d f$ & MS & $F$-Test & $p$-Value \\
\hline Group & 2784.709 & 1 & 2784.709 & 7.303 & 0.009 \\
\hline Pre-test & 4611.843 & 1 & 4611.843 & 2.094 & $0.001^{* * *}$ \\
\hline Error (between groups) & 18685.343 & 49 & 381.334 & & \\
\hline
\end{tabular}


4.1.2. Differences in Learning Effectiveness Using AR-Based and General Health Education Board Game

The following Table 5 shows the results of the independent sample t-test. In the general board game part, where there were significant differences between the mean values of the pre-test and the post-test, $t(25)=-3.41, p=0.002, d=0.77$, post-test $(\mathrm{M}=51.20, \mathrm{SD}=21.63)$, and pre-test $(\mathrm{M}=37.12$, $\mathrm{SD}=13.88)$. The score of the post-test increased by 14.08 compared to that of the pre-test, and the increase in the learning effectiveness for subjects who experienced the general board game had a significance of 0.002 , which was significant, the effect size was $0.77>0.5$, which implied a medium effect. In the AR-based board game part, there were extremely significant differences between the mean values of the pre-test and the post-test, $t(27)=-7.076, p=0.000, d=1.406$, post-test $(\mathrm{M}=71.26$, $\mathrm{SD}=21.54)$, pre-test $(\mathrm{M}=44.74, \mathrm{SD}=15.73)$. The score of the post-test increased by 26.52 compared to that of the pre-test, and the increase in the learning effectiveness for subjects who experienced the AR-based board game had a significance of 0.000 , which was extremely significant, the effect size was $1.406>0.8$, which implied a big effect.

Table 5. Learning effectiveness of test subjects from playing a general board game and AR-based board game.

\begin{tabular}{|c|c|c|c|c|c|c|c|}
\hline \multirow{2}{*}{ Score } & \multirow{2}{*}{$\mathbf{N}$} & \multicolumn{2}{|c|}{ Mean (SD) } & \multirow[t]{2}{*}{$d f$} & \multirow{2}{*}{$t$-Value } & \multirow{2}{*}{$p$-Value } & \multirow{2}{*}{$d$-Value } \\
\hline & & Pre-Test & Post-Test & & & & \\
\hline G & 25 & $\begin{array}{c}37.12 \\
(13.88)\end{array}$ & $\begin{array}{c}51.20 \\
(21.63)\end{array}$ & 24 & -3.41 & $0.002^{* *}$ & 0.77 \\
\hline $\mathrm{AR}$ & 27 & $\begin{array}{c}44.74 \\
(15.73)\end{array}$ & $\begin{array}{l}71.26 \\
(21.54)\end{array}$ & 26 & -7.076 & $0.000^{* * *}$ & 1.406 \\
\hline
\end{tabular}

${ }^{* *} p<0.01,{ }^{* * *} p<0.001$, Note: general board game (G), AR-based board game (AR).

The results show that both groups evidently improved. Through the analysis of the mean value for the post-test, we found that the average score of the learning effectiveness for subjects who experienced the general board game was 52, and the average score of the learning effectiveness for subjects who experienced the AR-based board game was 71.26, which indicated that the learning effectiveness of the AR-based board game test subjects was higher than that of the general board game test subjects, and the effect size for the AR-based board game test subjects was also higher than that of the general board game test subjects. Table 6 indicates the following information, there are significant differences between the experimental group and the control group for the post-test, $t(50)=-3.34, p=0.002$. There are significant differences between the post-test $(\mathrm{M}=51.2, \mathrm{SD}=21.63)$ of the control group and the post-test of the experimental group $(\mathrm{M}=71.26, \mathrm{SD}=21.54)$, with a significance of $0.003<0.05$ between the two, which indicated the significant differences between the two groups.

Table 6. Learning effectiveness of test subjects from playing an augmented reality (AR)-based board game.

\begin{tabular}{|c|c|c|c|c|c|}
\hline & \multicolumn{2}{|c|}{ Mean (SD) } & \multirow[b]{2}{*}{$d f$} & \multirow[b]{2}{*}{$t$-Value } & \multirow[b]{2}{*}{$p$-Value } \\
\hline & $\begin{array}{l}\text { Control Group } \\
\quad(N=25)\end{array}$ & $\begin{array}{l}\text { Experimental Group } \\
(\mathbf{N}=27)\end{array}$ & & & \\
\hline Post-test & $51.2(21.63)$ & $71.26(21.54)$ & 50 & -3.34 & $0.002 * *$ \\
\hline
\end{tabular}




\subsection{Differences in Learning Emotion by Using AR in the Health Education Board Game}

\subsubsection{Analysis of the Emotional Manifestation before Learning}

Table 7 shows the results of the independent sample t-test of emotional manifestation before, during and after learning. In before learning, there were no significant differences for the pre-test between the experimental group and the control group, $t(50)=0.308, p=0.759$. There were no significant differences between the emotional score $(\mathrm{M}=3.45, \mathrm{SD}=0.461)$ of the control group before learning and the emotional score $(\mathrm{M}=3.49, \mathrm{SD}=0.401)$ of the experimental group before learning, with a significance of $0.759>0.05$, which explained that there were no major differences in the emotional manifestation before learning between the test subjects of the two groups. In during learning, there were extremely significant differences between the mean values of the experimental group and those of the control group, $t(50)=-2.285, p=0.027$. There were significant differences between the emotional score $(\mathrm{M}=3.46, \mathrm{SD}=0.466)$ of the control group during learning and the emotional score $(\mathrm{M}=3.73$, $\mathrm{SD}=0.370$ ) of the experimental group during learning, with a significance of $0.027<0.05$ between the two, which explained that there were significant differences in the emotional manifestation during learning between the test subjects of the two groups. In after learning, there were extremely significant differences between the mean values of the experimental group and those of the control group for the post-test, $t(50)=-3.551, p=0.001$. There were significant differences between the emotional score $(\mathrm{M}=3.54, \mathrm{SD}=0.441)$ of the control group after learning and the emotional score $(\mathrm{M}=3.98, \mathrm{SD}=0.454)$ of the experimental group after learning, with a significance of $0.001<0.05$, which explained the significant differences in the manifestation after learning between the test subjects of the two groups.

Table 7. The emotional manifestation before, during and after learning.

\begin{tabular}{|c|c|c|c|c|c|}
\hline \multirow[b]{2}{*}{ AEQ } & \multicolumn{2}{|c|}{ Mean (SD) } & \multirow[b]{2}{*}{$d f$} & \multirow[b]{2}{*}{$t$} & \multirow[b]{2}{*}{$p$} \\
\hline & $\begin{array}{l}\text { Control Group } \\
\quad(\mathrm{N}=25)\end{array}$ & $\begin{array}{l}\text { Experimental Group } \\
\qquad(\mathrm{N}=27)\end{array}$ & & & \\
\hline before & $3.45(0.461)$ & $3.49(0.401)$ & 50 & -0.308 & 0.759 \\
\hline during & $3.46(0.466)$ & $3.73(0.370)$ & 50 & -2.285 & $0.027 * *$ \\
\hline after & $3.54(0.441)$ & $3.98(0.454)$ & 50 & -3.551 & 0.001 ** \\
\hline
\end{tabular}

\subsubsection{Analysis of Learning Emotional Manifestation-Eight Emotions}

Table 8 shows the results of the independent sample $t$-test of eight emotions. In the enjoyment part, there were no significant differences in the mean values of the score between the experimental group and the control group, $t(50)=-1.858, p=0.069$. There were no significant differences between the enjoyment score $(\mathrm{M}=3.52, \mathrm{SD}=0.551)$ for the learning emotion of the control group and the enjoyment score $(\mathrm{M}=3.79, \mathrm{SD}=0.461)$ for the learning emotion of the experimental group, with a significance of $0.069>0.05$ between the two, which implied that there were no significant differences between the two groups. The result shows that the mean value for the two groups was higher than the median of three, which indicated that both the groups exhibited emotional manifestation of enjoyment and that both the groups exhibited the same level of changes regarding this specific emotion.

In the hope part, there were no significant differences in the mean values of the score between the experimental group and the control group, $t(50)=-0.321, p=0.750$. There were no significant differences between the hope score $(\mathrm{M}=3.42, \mathrm{SD}=0.425)$ for the learning emotion of the control group and the hope score $(\mathrm{M}=3.46, \mathrm{SD}=0.368)$ for the learning emotion of the experimental group, with a significance of $0.750>0.05$ between the two, which implied that there were no significant differences between the two groups. The result shows that the mean value for the two groups was higher than the median of three, which indicated that both the groups exhibited the emotional manifestation of hope 
during the course of gameplay and that both the groups exhibited the same level of changes regarding the specific emotion.

Table 8. Learning emotional manifestation of eight emotions.

\begin{tabular}{|c|c|c|c|c|c|}
\hline \multirow[b]{2}{*}{ Emotions } & \multicolumn{2}{|c|}{ Mean (SD) } & \multirow[b]{2}{*}{$d f$} & \multirow[b]{2}{*}{$t$-Value } & \multirow[b]{2}{*}{$p$-Value } \\
\hline & $\begin{array}{l}\text { Control Group } \\
\quad(\mathrm{N}=25)\end{array}$ & $\begin{array}{c}\text { Experimental Group } \\
(\mathbf{N}=27)\end{array}$ & & & \\
\hline Enjoyment & $3.52(0.551)$ & $3.79(0.461)$ & 50 & -1.858 & 0.069 \\
\hline Hope & $3.42(0.425)$ & $3.46(0.368)$ & 50 & -0.321 & 0.750 \\
\hline Pride & $3.38(0.540)$ & $3.63(0.534)$ & 50 & -1.170 & 0.095 \\
\hline Anger & $3.56(0.479)$ & $3.82(0.406)$ & 50 & -2.168 & $0.035^{* *}$ \\
\hline Anxiety & $3.43(0.487)$ & $3.64(0.369)$ & 50 & -1.814 & 0.076 \\
\hline Shame & $3.54(0.526)$ & $3.86(0.419)$ & 50 & -2.371 & 0.022 ** \\
\hline Hopelessness & $3.44(0.463)$ & $3.76(0.283)$ & 50 & -2.988 & $0.004^{* *}$ \\
\hline Boredom & $3.50(0.526)$ & $3.77(0.417)$ & 50 & -2.059 & $0.045^{* *}$ \\
\hline Overall Flow & $3.33(0.645)$ & $4.03(0.447)$ & 50 & -5.452 & $0.000 * *$ \\
\hline
\end{tabular}

In the pride part, there were no significant differences in the mean values of the score between the experimental group and the control group, $t(50)=-1.170, p=0.095$. There were no significant differences between the pride score $(\mathrm{M}=3.38, \mathrm{SD}=0.540)$ for the learning emotion of the control group and the pride score $(\mathrm{M}=3.63, \mathrm{SD}=0.534)$ for the learning emotion of the experimental group, with a significance of $0.095>0.05$ between the two, which implied that there were no significant differences between the two groups. The result shows that the mean value for the two groups was higher than the median of three, which indicated that both the groups exhibited the emotional manifestation of pride during the course of gameplay and that both the groups exhibited the same level of changes regarding the specific emotion.

In the anger part, there were significant differences in the mean values of the score between the experimental group and the control group, $t(50)=-0.321, p=0.750$. There were significant differences between the anger score $(\mathrm{M}=3.56, \mathrm{SD}=0.479)$ for the learning emotion of the control group and the anger score $(\mathrm{M}=3.82, \mathrm{SD}=0.406)$ for the learning emotion of the experimental group, with a significance of $0.035<0.05$ between the two, which implied that there were significant differences between the two groups. The result shows that the mean value for the two groups was higher than the median of three, which indicated that both the groups exhibited relatively less emotional manifestation changes in anger during the course of gameplay and that the experimental group exhibited less emotional manifestation changes in anger than the control group.

In the anxiety part, there were no significant differences in the mean values of the score between the experimental group and the control group, $t(50)=-1.814, p=0.076$. There were no significant differences between the anxiety score $(\mathrm{M}=3.43, \mathrm{SD}=0.487)$ for the learning emotion of the control group and the anxiety score $(\mathrm{M}=3.62, \mathrm{SD}=0.369)$ for the learning emotion of the experimental group, with a significance of $0.076>0.05$ between the two, which indicated that there were no significant differences between the two groups. The result shows that the mean value for the two groups was higher than the median of three, which indicated that both the groups exhibited relatively less emotional manifestation changes in anxiety during the course of gameplay.

In the shame part, there were significant differences in the mean values of the score between the experimental group and the control group, $t(50)=-2.371, p=0.022$. There were significant differences between the shame score $(\mathrm{M}=3.54, \mathrm{SD}=0.526)$ for the learning emotion of the control group and the shame score $(\mathrm{M}=3.86, \mathrm{SD}=0.419)$ for the learning emotion of the experimental group, with a significance of $0.022<0.05$ between the two, which implied that there were significant differences between the two groups. The result shows that the mean value for the two groups was higher than the median of three, which indicated that both the groups exhibited relatively less emotional manifestation 
changes in shame during the course of gameplay, and that the experimental group exhibited less emotional manifestation changes in shame than the control group.

In the hopelessness part, there were significant differences in the mean values of the score between the experimental group and the control group, $t(50)=-2.988, p=0.004$. There were significant differences between the hopelessness score $(\mathrm{M}=3.44, \mathrm{SD}=0.463)$ for the learning emotion of the control group and the hopelessness score $(\mathrm{M}=3.76, \mathrm{SD}=0.283)$ for the learning emotion of the experimental group, with a significance of $0.004<0.05$ between the two, which implied that there were significant differences between the two groups. The result shows that the mean value for the two groups was higher than the median of three, which indicated that both the groups exhibited relatively less emotional manifestation changes in hopelessness during the course of gameplay and that the experimental group exhibited less emotional manifestation changes in hopelessness than the control group.

In the boredom part, there were significant differences in the mean values of the score between the experimental group and the control group, $t(50)=-2.059, p=0.045$. There were minor differences between the boredom score $(\mathrm{M}=3.50, \mathrm{SD}=0.526)$ for the learning emotion of the control group and the boredom score $(\mathrm{M}=3.77, \mathrm{SD}=0.417)$ for the learning emotion of the experimental group, with a significance of $0.045>0.05$, which implied that there were minor differences between the two groups. The result shows that the mean value for the two groups was higher than the median of three, which indicated that both the groups exhibited relatively less emotional manifestation changes in boredom during the course of gameplay and that the experimental group exhibited less emotional manifestation changes in boredom than the control group.

\subsection{Game Flow Analysis for the Two Groups-Overall Flow}

Table 8 shows the results of the overall flow analysis for the two groups subsequent to gameplay by using independent sample t-test. There were significant differences in the mean values of the post-test flow score between the experimental group and the control group, $t(50)=-5.452, p=0.000$. There were significant differences between the post-test flow score $(\mathrm{M}=3.33, \mathrm{SD}=0.645)$ of the control group and the post-test flow score $(\mathrm{M}=4.03, \mathrm{SD}=0.447)$ of the experimental group, with a significance of $0.000<0.05$ between the two, which implied that there were significant differences between the two groups. The result shows that the mean value for the two groups was higher than the median of three, which indicated that both the groups exhibited changes in feelings, although the test subjects from the experimental group, who experienced AR in the board game, exhibited more evident feelings.

\section{Conclusions and Discussion}

Board games have been applied to various courses in many academic studies, but they are rarely used in health education. According to Chan [4], in traditional school education, students are commonly restricted by the education system, and the content of health education courses cannot be easily linked to learners' everyday experiences. Therefore, the mechanism of this study may solve this problem. AR integrated with games provides a solution to the missing connection between health education courses and daily-life scenarios.

The novelty of this study lies in the discussion of the affective aspect and flow experience, as previous research on AR and board games seldom have explored these determinants. The present study assessed various emotions to understand the details of learning emotions among users of AR-based board games and revealed that learners who used AR-based board games had positive attitudes when learning.

The aim of this study was to design an educational augmented reality (AR)-based board game and apply it to health education through the incorporation of CSLS. To analyze participants' learning effectiveness when using the AR-based board game and a typical board game and investigate their influence on learning, we compared the differences in eight learning emotions. We then analyzed these 
differences throughout the game progression. The results of the three research questions indicated that integrating AR into a board game yielded the following changes:

1. The learning effectiveness was significantly affected by the integration of AR into the health education board game, and the application of the AR-based board game effectively helped learners to improve their learning effectiveness. The results confirm those of previous studies, in which AR has been shown to enhance learning $[9,10,19,29]$. In addition, we revealed that the learning outcomes and effectiveness among participants using the AR-based board game were superior to those of the participants who used regular board games. Hence, AR-based board games are effective in improving learning outcomes. This echoes the research showed that the combination of AR and board games could improve the effectiveness of student learning [21,30].

2. Emotion is important in education, it drives attention, which in turn drives learning and memory [31]. This echoes the point of Ammar et al. [32], who found that emotions play an important role in learning. Emotions may become a boost or a hindrance to learning. Among the learning emotions, we observed significant differences in negative emotions of learners using the AR-based and typical board games-learners who used the AR-based board game learned with a positive attitude. Previous studies have indicated that AR applications in education induce proactivity in students $[11,33,34]$. The novelty of this study lies in the discussion of the affective aspect and flow experience, as previous research on AR and board games seldom explored these determinants. The present study assessed various emotions to understand the details of learning emotions among users of AR-based board games and revealed that learners who used AR-based board games had positive attitudes when learning, an effect that has also been observed in typical board games but the results are significantly better in the case of the AR-based board game. From the analysis of the results of learning emotions in the pre, middle, and post-tests, we can see the significant effects of the two groups of regular board games and augmented reality board games. The results show that augmented reality board games can effectively help learners improve their learning emotions.

3. Many studies have conducted experiments and discussions on the relationship between board games and flow experience. Research results show that learning using board games enables learners to become more engaged in learning, helps improve memory, and further enhances learning effectiveness. However, there is little research on the combination of augmented reality and board games in teaching to explore the flow experience. Therefore, this research explores the difference in game flow when augmented reality and health education board games are combined. The game flow differed significantly between the AR-based and typical board games. In the AR-based board game, learners were more deeply immersed in the course of the gameplay and thus achieved more effective learning. The results confirm those of previous studies, in which AR integration enabled students to be more involved in learning, thus improving the flow $[5,35,36]$.

Future studies can use three-dimensional displays for the AR identification screen. To improve observation among learners, various sensory experiences can be introduced, thus enhancing their learning motivation. Future studies are recommended to integrate AR in various types of board games to enhance these effects for learning new knowledge. Finally, to deepen the understanding of the effect of AR integration in health education board games on learning outcomes and learning emotions, we advise future studies to incorporate interviews with learners. Qualitative data would help reveal specific feelings that learners experience when participating in AR-based health education and further demonstrate detailed changes in their health education knowledge and learning emotions.

Author Contributions: H.-C.K.L. and L.-K.S. conceived and designed the experiments; L.-K.S. performed the experiments; T.-H.W. and Y.-M.H. analyzed the data; H.-C.K.L. contributed reagents/materials/analysis tools; Y.-H.L. wrote the paper. All authors have read and agreed to the published version of the manuscript.

Funding: This research received no external funding.

Conflicts of Interest: The authors declare no conflict of interest. 


\section{References}

1. Brown, J.S.; Collins, A.; Duguid, P. Situated cognition and the culture of learning. Educ. Res. 1989, 18, 32-42. [CrossRef]

2. Dunleavy, M.; Dede, C. Augmented reality teaching and learning. In Handbook of Research on Educational Communications and Technology; Springer: New York, NY, USA, 2014; pp. 735-745.

3. Shen, H.; Li, C.T.; Wang, S.M.; Hou, H.T. Applying Gamification Teaching Activity Using Card-Games, Slides and Learning Sheets (CSLS) for High School Chemistry Instruction. In Proceedings of the 22nd Global Chinese Conference on Computer Education, Canton, China, 25-29 May 2017.

4. Chan, J.C. Apply Problem-Based Learning on Sharable Health Education Learning Material; Taipei Medical University: Taipei City, Taiwan, 2004.

5. Ibáñez, M.B.; Di Serio, Á.; Villarán, D.; Kloos, C.D. Experimenting with electromagnetism using augmented reality: Impact on flow student experience and educational effectiveness. Comput. Educ. 2014, 71, 1-13. [CrossRef]

6. Zhang, J.; Sung, Y.-T.; Hou, H.-T.; Chang, K.-E. The development and evaluation of an augmented reality-based armillary sphere for astronomical observation instruction. Comput. Educ. 2014, 73, 178-188. [CrossRef]

7. Tian, K.; Urata, M.; Endo, M.; Mouri, K.; Yasuda, T.; Kato, J. Real-World Oriented Smartphone AR Supported Learning System Based on Planetarium Contents for Seasonal Constellation Observation. Appl. Sci. 2019, 9 , 3508. [CrossRef]

8. Chang, K.-E.; Chang, C.-T.; Hou, H.-T.; Sung, Y.-T.; Chao, H.-L.; Lee, C.-M. Development and behavioral pattern analysis of a mobile guide system with augmented reality for painting appreciation instruction in an art museum. Comput. Educ. 2014, 71, 185-197. [CrossRef]

9. Akçayır, M.; Akçayır, G. Advantages and challenges associated with augmented reality for education: A systematic review of the literature. Educ. Res. Rev. 2017, 20,1-11. [CrossRef]

10. Billinghurst, M.; Belcher, D.; Gupta, A.; Kiyokawa, K. Communication Behaviors in Colocated Collaborative AR Interfaces. Int. J. Hum.-Comput. Interact. 2003, 16, 395-423. [CrossRef]

11. Akçayır, M.; Akçayır, G.; Pektaş, H.M.; Ocak, M.A. Augmented reality in science laboratories: The effects of augmented reality on university students' laboratory skills and attitudes toward science laboratories. Comput. Hum. Behav. 2016, 57, 334-342. [CrossRef]

12. Wei, X.; Weng, D.; Liu, Y.; Wang, Y. Teaching based on augmented reality for a technical creative design course. Comput. Educ. 2015, 81, 221-234. [CrossRef]

13. Kafai, Y.B. Minds in Play: Computer Game Design as a Context for Children's Learning; Routledge: London, UK, 2012.

14. Bouzid, Y.; Khenissi, M.A.; Essalmi, F.; Jemni, M. Using educational games for sign language learning-a signwriting learning game: Case study. J. Educ. Technol. Soc. 2016, 19, 129-141.

15. Qian, M.; Clark, K.R. Game-based Learning and 21st century skills: A review of recent research. Comput. Hum. Behav. 2016, 63, 50-58. [CrossRef]

16. Pesare, E.; Roselli, T.; Corriero, N.; Rossano, V. Game-based learning and Gamification to promote engagement and motivation in medical learning contexts. Smart Learn. Environ. 2016, 3, 5. [CrossRef]

17. De Carvalho, C.; Coutinho, R.F.; Lima, I.D.D.A.; De Leon, C.G.R.M.P.; Ribeiro, L.M.; Vieira, G.B.; Guarda, L.E.D.A.; Paula, R.A.P.; Dos Santos, S.R. Evaluation of Board Game about Immunopreventable Diseases for Higher Education in Health Course. Creative Educ. 2018, 9, 646-657. [CrossRef]

18. Kuo, W.W. A Study of Using Board Games to Improve Elementary School Students' English Reading Ability and Learning Attitudes; University of Kang Ning: Tainan City, Taiwan, 2017.

19. Li, C.-T.; Wang, P.-Y.; Chen, K.-T.; Kuo, C.-C.; Hou, H.-T. An augmented reality educational board game with situated learning and scaffolding teaching strategy for environmental protection issue. In Proceedings of the ICCE 2017-25th International Conference on Computers in Education: Technology and Innovation: Computer-Based Educational Systems for the 21st Century, Work in Progress Posters Proceedings, Christchurch, New Zealand, 4-8 December 2017.

20. Wang, M.-C. A Study on the Effectiveness of Applying Board Games and Augmented Reality Board Games to Anti-Drug Education Among Senior High-School Students. Master's Thesis, National Taiwan Normal University, Taipei City, Taiwan, 2020; pp. 1-105. 
21. Wang, P.Y.; Lin, H.T.; Wang, S.M.; Hou, H.T. The development and evaluation of an educational board game with augmented reality integrating contextual clues as multi-level scaffolding for learning ecosystem concepts. In Proceedings of the 2019 IEEE International Conference on Consumer Electronics-Taiwan (ICCE-TW), Yilan, Taiwan, 20-22 May 2019; pp. 1-2.

22. Wood, D.; Bruner, J.S.; Ross, G. The role of tutoring in problem solving. J. Child Psychol. Psychiatry 1976, 17, 89-100. [CrossRef] [PubMed]

23. Paivio, A. Imagery and language. In Imagery; Academic Press: Cambridge, MA, USA, 1971; pp. 7-32.

24. Ebbinghaus, H. Über das Gedächtnis: Untersuchungen zur Experimentellen Psychologie; Duncker \& Humblot: Berlin, Germany, 1885.

25. Burguillo, J.C. Using game theory and Competition-based Learning to stimulate student motivation and performance. Comput. Educ. 2010, 55, 566-575. [CrossRef]

26. Pekrun, R.; Goetz, T.; Perry, R.P.J.U.M. Achievement Emotions Questionnaire (AEQ); User's Manual; University of Munich: Munich, Germany, 2005.

27. Kiili, K. Digital game-based learning: Towards an experiential gaming model. Internet High. Educ. 2005, 8, 13-24. [CrossRef]

28. Hou, H.-T.; Chou, Y.-S.J.I. Exploring the technology acceptance and flow state of a chamber escape game-escape the lab for learning electromagnet concept. In Proceedings of the 20th International Conference on Computers in Education, Singapore, 26 November 2012; Volume 38.

29. Lin, Y.H.; Lin, H.C.K. Using an augmented-reality board game for drug addiction prevention at a University in Taiwan. In International Conference on Innovative Technologies and Learning; Springer: Berlin/Heidelberg, Germany, 2019; pp. 24-32.

30. Yu, J.; Denham, A. Analyzing the effects of a culturally relevant augmented reality math board game on lakota students' arithmetic performances: A case study. In E-Learn: World Conference on E-Learning in Corporate, Government, Healthcare, and Higher Education; Association for the Advancement of Computing in Education (AACE): San Diego, CA, USA, 2019; pp. 606-610.

31. Sylwester, R. How emotions affect learning. Educ. Leadersh. 1994, 52, 60-65.

32. Ben Ammar, M.; Neji, M.; Alimi, A.M.; Gouardères, G. The Affective Tutoring System. Expert Syst. Appl. 2010, 37, 3013-3023. [CrossRef]

33. Huang, T.-C.; Chen, C.-C.; Chou, Y.-W. Animating eco-education: To see, feel, and discover in an augmented reality-based experiential learning environment. Comput. Educ. 2016, 96, 72-82. [CrossRef]

34. Poitras, E.G.; Harley, J.M.; Liu, Y.S. Achievement emotions with location-based mobile augmented reality: An examination of discourse processes in simulated guided walking tours. Br. J. Educ. Technol. 2019, 50, 3345-3360. [CrossRef]

35. Lee, H.; Cha, S.-A.; Kwon, H.-N. Study on the Effect of Augmented Reality Contents-Based Instruction for Adult Learners on Academic Achievement, Interest and Flow. J. Korea Contents Assoc. 2016, 16, 424-437. [CrossRef]

36. Noh, K.-H.; Jee, H.-K.; Lim, S.-H. Effect of Augmented Reality Contents Based Instruction on Academic Achievement, Interest and Flow of Learning. J. Korea Contents Assoc. 2010, 10, 1-13. [CrossRef]

Publisher's Note: MDPI stays neutral with regard to jurisdictional claims in published maps and institutional affiliations.

(C) 2020 by the authors. Licensee MDPI, Basel, Switzerland. This article is an open access article distributed under the terms and conditions of the Creative Commons Attribution (CC BY) license (http://creativecommons.org/licenses/by/4.0/). 